\title{
Consanguinity and Prevalence Patterns of Inherited Disease in the UK Pakistani Community
}

\author{
Peter C. Corry \\ Bradford Institute for Health Research, Bradford Royal Infirmary, Bradford, UK
}

\section{Key Words}

Consanguinity · Inherited disease - UK Pakistani community .

Autosomal recessive conditions

\begin{abstract}
Objectives: The aim of this paper is to describe the current knowledge about inherited diseases in UK children of Pakistani origin, who now number over 300,000, and to investigate disease associations with parental consanguinity. Methods: Published data on the overall prevalence of inherited diseases were reviewed in conjunction with published and unpublished information from the city of Bradford where there is a large resident Pakistani community. Results: There is significant literature on infant mortality, congenital anomalies, disabilities and many clinical conditions, often drawing attention to ethnic variations and an increased disease prevalence in UK Pakistani children. A further analysis is frequently necessary to differentiate both between genetic and non-genetic causes, and Pakistani and non-Pakistani children, who collectively have been labelled as 'Asian' or 'South Asian'. Conclusions: The analysis suggests that much of the increased mortality and morbidity in UK Pakistani children is due to autosomal recessive conditions. Evidence suggests that this finding is associated with the custom of consanguineous marriage, but future
\end{abstract}

studies might also explore the role of community endogamy. Prevalence data from the first and second post-migration generations could additionally be useful in informing health planning in Pakistan.

(c) 2014 S. Karger AG, Basel

\section{Introduction}

The last half century has seen major changes in the population profiles of many European countries. In the UK this has been manifest in immigration from the former British Empire, in particular with large numbers arriving from the Indian subcontinent. Data from the Office for National Statistics for mid-2009 estimated that there were about 9.7 million children (aged $0-15$ years) in England, of whom 292,000 (3.0\%) were of Pakistani origin. As is common for many newly established migrant communities, British Pakistanis are mostly concentrated in particular urban locations, including the cities of Birmingham in the English Midlands and Bradford in the Northern English county of Yorkshire. Thus, the Office for National Statistics' mid-2009 data for Bradford lists 114,500 children, of whom 24,700 (21.6\%) are Pakistani, 3,300 (2.9\%) Indian, 3,200 (2.8\%) Bangladeshi, and 1,200 (1.0\%) 'Other Asian' [1].

\section{KARGER}

E-Mail karger@karger.com

www.karger.com/hhe
(C) 2014 S. Karger AG, Basel

0001-5652/14/0774-0207\$39.50/0
Peter C. Corry

Bradford Institute for Health Research, Bradford Royal Infirmary Duckworth Lane

Bradford, BD9 6RJ (UK)

E-Mail pccorry@btinternet.com 
Table 1. Births at Bradford Royal Infirmary from January 1, 2012, to December 31, 2012

\begin{tabular}{lll}
\hline & Births, $\mathrm{n}$ & Percentage \\
\hline Pakistani & 2,521 & 41.8 \\
White British & 2,057 & 34.2 \\
Other & 1,444 & 23.9 \\
\hline Total & 6,022 & \\
\hline
\end{tabular}

Over the years there has been a gradual increase in the number and proportions of Pakistani births in Bradford. Between 2001 and 2003, deliveries to Pakistani women increased from 31.2 to $38.5 \%$ of total births [2], while data collected on births at Bradford Royal Infirmary in 2012 showed that $41.8 \%$ were Pakistani, by comparison with 34.2\% White British (table 1).

As in their country of origin, UK Pakistanis favour consanguineous marriage as well as endogamous unions within traditional groupings known as biraderi. Consanguineous marriage is generally defined as a union between two people sharing one or more common ancestors, and from a medical genetics perspective it refers to marriage between a couple related as second cousins or closer $(F \geq 0.0156)$ [3]. Biraderi unions are contracted on the basis of social/occupational groups, but the marriage patterns may also reflect religious sub-groupings and/or geographical loyalties.

Consanguineous marriage is common in many other new UK immigrant groups, including those from the Middle East, Turkey, Iran, North Africa, and South India, and longer established communities such as the Irish Travellers. Recent public attention has, however, focused largely on the Pakistani community, in part because of its large numbers coupled with high rates of consanguinity $[4,5]$. Thus a recent prospective health-based study in Bradford indicated that $1,922(37.5 \%)$ of 5,127 Pakistani mothers were married to first cousins, with a further $1,116(21.8 \%)$ married to other blood relatives [6].

While these marriage patterns may seem unusual to Western commentators, consanguinity was more frequent in the general population of Western Europe and North America until the latter half of the 19th century and it continues to be favoured in specific sub-groups, including social minorities such as the Roma [7], and in religious and geographical isolates [8]. Many of these communities are typified by a high incidence of specific genetic disorders [9], e.g. the Finnish genetic heritage, in which there is a significant increase in more than 30 otherwise very rare conditions [10].

\section{Data Sources in the UK}

The National Registration of Births and Deaths was established in Great Britain during the 1830s and a decennial National Census was introduced in 1841. Estimates of ethnicity are made by the Office for National Statistics, although very broad categories such as 'Asian' are more readily available than descriptors of specific national origins. The term 'South Asian' is sometimes applied interchangeably with 'Asian'; although in current UK statistics, members of the Chinese community are separately identified.

A regular system for the registration of congenital anomalies began in the 1960s, following the thalidomide epidemic. However, its accuracy and effective coverage have recently been queried [11], and in the past the system did not record terminations of pregnancy for congenital anomalies. In addition, about one-third of England is covered by more complete local registers via the British Isles Network of Congenital Anomaly Registers (BINOCAR), and Public Health England has recently committed to expanding this form of coverage to the whole of England [12].

There is an increasing worldwide interest in rare diseases. The British Paediatric Surveillance Unit began their studies on unusual clinical conditions in 1986, and several of these studies have drawn attention to variations in the prevalence and pattern of rare diseases in differing ethnic communities. The increasing development of patient registers for rare conditions is thus also likely to be a useful future resource. While there is a wealth of UK data about childhood diseases, little is available directly linking genetic conditions with consanguinity. There are studies of particular conditions, or groups of conditions, but many include non-genetic causation. Where information on ethnicity exists, it may be limited to the somewhat uninformative descriptor 'Asian', encompassing people from the Indian subcontinent but not clearly identifying those of Pakistani heritage. Likewise, there are varying opinions about the precise definition of childhood, with cutoff points somewhere between the 16th and 19th birthday applied.

Several birth cohort studies have been undertaken in the UK, e.g. the Birmingham Study [13], but to date the currently ongoing Born in Bradford (BiB) study has investigated the largest number of British Pakistani chil- 
dren as well as over 4,000 White British births [14]. This initiative follows more than 13,000 children born between 2007 and 2010. Pregnant women were recruited at the end of the second trimester, giving informed consent and providing detailed demographic information during a structured interview conducted either in English or the respondents' South Asian language of choice. The $\mathrm{BiB}$ cohort is representative of the city's multi-ethnic population, with $45 \%$ of the mothers being Pakistani, 39\% of White British origin, and 15\% from other ethnic groups [15]. However, from a disease incidence perspective, the nature of the study means that data are not available on terminations of pregnancy following antenatal screening.

\section{Reports on Deaths and Life-Limiting Conditions}

National data for births and deaths are collected regularly and reports can be interrogated for rates by district and ethnicity. Infants of Pakistani origin experience high levels of mortality, e.g. in 2005 the infant mortality rate (IMR) was 9.6 per 1,000 for Pakistani infants, compared with 5.0 per 1,000 for all live births in England and Wales [16]. As in the rest of England, in Bradford there has been a gradual reduction in infant mortality, but the IMR for births in the city during the period of 2009-2010 (7.5 per $1,000)$ has remained significantly above that for England as a whole (4.4 per 1,000).

There has been a recent government-led focus on reducing the IMR, and the introduction of relevant legislation in 2008 led to a national system of Child Death Overview Panels. These Panels are now starting to produce more detailed information on the causes of infant deaths and they are also considering childhood deaths after the first year of life. As indicated in table 2, the report of the Bradford Panel for the year April 2011 to April 2012 demonstrated an excess of child deaths for South Asian, mainly Pakistani, children during the periods of 2008-2009 and 2009-2010.

A further analysis of the Bradford data on the causes of childhood deaths showed a large increase in deaths of South Asian children, which were ascribed to chromosomal, genetic and congenital anomalies (category 7), while those due to perinatal/neonatal events (category 8) were approximately equal in prevalence between South Asian and non-South Asian children (table 3). As these two categories accounted for $73 \%$ of all childhood deaths, deaths in the other 8 categories were not disaggregated by ethnicity in the Child Death Overview Panels report.

Consanguinity and Prevalence Patterns of Inherited Disease

Table 2. Bradford child deaths by ethnicity

\begin{tabular}{lcc}
\hline & $2008-2009, \mathrm{n}(\%)$ & $2009-2010, \mathrm{n}(\%)$ \\
\hline South Asian & $53(63.1)$ & $62(65.0)$ \\
White British or Irish & $24(28.6)$ & $30(31.6)$ \\
Other $^{\mathrm{a}}$ & $7(8.3)$ & $4(4.2)$ \\
\hline All & $84(100)$ & $95(100)$ \\
\hline
\end{tabular}

Source: CDOP Annual Report 2011/2012 Bradford Safeguarding Children Board (http://bradford-scb.org.uk/cdop.htm). a Including the Eastern European ethnicity.

Table 3. Cause of death for children $<18$ years of age by ethnicity for the period of 2008-2012 $\begin{array}{ll}\text { South Asian } & \begin{array}{l}\text { Non-South Total } \\ \text { Asian }\end{array}\end{array}$

Chromosomal, genetic and congenital anomalies Perinatal/neonatal events

$98(82.4) \quad 21(17.6)$

$119(100)$

(50.0)

Values are given in $\mathrm{n}$ (\%). Source: CDOP Annual Report 2011/ 2012 Bradford Safeguarding Children Board (http://bradford-scb. org.uk/cdop.htm).

Attempts have also been made to estimate the number of children with life-limiting conditions. In many ways, the extended morbidity experienced by these children may have a longer-lasting impact on their families as well as on the health and other services. In this respect, a recent paper reported that the number of South Asian children with life-limiting conditions was 47.6 per 10,000 compared with 27.0 per 10,000 for White British children [17].

\section{Information on Inherited Diseases from other Data Sources}

There have been some attempts to focus on autosomal recessive conditions which are likely to be increased in customarily consanguineous communities. In a 2005 letter to the British Medical Journal, Asian children in the Northern English town of Blackburn were shown to have a 12-fold increase in the likelihood of having a recessive disorder, with 13 new recessive disorders per 1,000 births 
[18]. Similarly, a presentation at the 2004 Annual Meeting of the Royal College of Paediatrics and Child Health reported that 83 different recessive conditions had been identified in Blackburn children [19].

An on-going review of autosomal recessive conditions in Bradford children has identified almost 200 conditions since 2000, with the majority of these disorders diagnosed in the city's Pakistani community. This estimate covers the whole range of paediatric diseases and includes rare causes of deafness and visual impairment, life-limiting skin conditions, muscle disorders, and haemoglobinopathies as well as inborn errors of metabolism. In terms of absolute numbers, this is likely to represent some 1,000 of 30,000 Pakistani children resident in the district. However, it must be stressed that as yet the review has not been systematic, and it lacks access to patient names or ethnicity. An ethically approved study, incorporating a formal reporting system, would be a necessary prerequisite to quantify the situation in detail.

Morton et al. [20] reported in a 2002 paper from the East Midlands city of Derby that there was a significant increase in severe learning disability, severe and profound hearing loss, and severe visual impairment in Pakistani children, with $2 \%$ of local Pakistani children attending the Child Development Centre compared with $0.56 \%$ of Indian and $0.78 \%$ of other children, mainly White British. On this basis they estimated a 10-fold increase in genetic problems among Pakistani versus nonPakistani children, but with approximately equal numbers affected by chromosomal disorders [20].

\section{Specific Conditions or Groups of Conditions}

\section{Inborn Errors of Metabolism}

These individually rare conditions are almost always genetic in origin and usually due to autosomal recessive mutations. Theoretically, they are likely to be present at an increased incidence in customarily consanguineous communities, and that indeed seems to be the case. A 1998 paper from the West Midlands of England reported on the birth prevalence for inborn errors of metabolism in a region where 707,720 children had been born in the 10-year period preceding the 1991 National Census [21]. By 1996, an inborn error of metabolism with autosomal recessive inheritance had been diagnosed in 263 of these children, with an incidence of 1 in 318 for Pakistani children compared with 1 in 3,760 for White British children [21].
Neurodegenerative conditions in children are usually, but not always, due to inborn errors of metabolism and genetic in origin, usually with an autosomal recessive mode of inheritance. Since 1997, the British Paediatric Surveillance Unit has been gathering case reports on neurodegenerative disorders in a monthly survey of paediatricians. The case definition for progressive intellectual and neurological deterioration (PIND) is 'any child (below 16 years of age at onset of symptoms) who fulfils the following criteria: progressive loss of already attained intellectual or developmental abilities and development of abnormal neurological signs', with comprehensive data collated on 1,483 children meeting these diagnostic criteria [22].

An increase in PIND has been noted in British Pakistani children, with districts such as Bradford and Birmingham reporting the largest numbers of cases, e.g. 89 cases reported in the Bradford district compared with an average of 9 cases per UK Health District [22]. A more detailed report from the UK PIND study focused on GM2 gangliosidoses [23], with Tay-Sachs disease, Sandhoff disease and GM2 activator protein deficiency identified in the study. Together these disorders comprised 73 (6.3\%) of 1,164 children with a diagnosed cause for PIND: 40 children (3.4\%) had Tay-Sachs disease, 31 (2.7\%) had Sandhoff disease and $2(0.2 \%)$ had activator protein deficiency. Of the 31 children with Sandhoff disease, 12 $(38.7 \%)$ were of Pakistani origin, which supports an earlier more specific analysis of 45 PIND patients in Bradford [24], of whom 39 were Pakistani, 5 White British, and 1 was of Middle Eastern origin. In 30 of these 45 children, the condition was known to be autosomal recessive [24]. The different neurodegenerative conditions diagnosed in Bradford Pakistani children from 1997 to 2013 are listed in table 4.

\section{Primary Microcephaly}

Primary microcephaly is a rare genetic condition causing a small head size and intellectual impairment. There is little available information on the global prevalence of the condition, but it became apparent in the 1990s that congenital microcephaly was significantly increased in Bradford children of Pakistani origin [24]. Of 35 patients in the author's practice, 7 were White British, 1 was Bangladeshi and 27 were Pakistani. Often, there was also a family history of microcephaly in the Pakistani families, and further investigations showed that most of this congenital microcephaly was indeed genetic in origin, with the first gene locus identified in 1998 and additional mutations subsequently described $[25,26]$. 
Table 4. Autosomal recessive neurodegenerative conditions diagnosed in Bradford Pakistani children in the period of 1997-2013

Aicardi-Goutières syndrome

Canavan disease

Cockayne syndrome

Cytochrome oxidase deficiency

GM1 gangliosidosis

GM2 gangliosidosis (juvenile Sandhoff disease)

Krabbe disease

Leigh disease

Metachromatic leucodystrophy

Molybdenum cofactor deficiency

Mucolipidosis type II (I-cell disease)

Mucolipidosis type IV

Mucopolysaccharidosis type I

Mucopolysaccharidosis type III

Niemann-Pick A

Niemann-Pick C

Neurodegeneration with brain iron accumulation PANK2

Neuronal ceroid lipofuscinosis

Pompe disease

Refsum disease

Wilson disease

Zellweger syndrome

\section{Cystic Fibrosis and Primary Ciliary Dyskinesia}

Cystic fibrosis is the most significant autosomal recessive cause of serious and life-limiting respiratory disease in Western Europe, affecting almost 1 in 2,000 children. Specialised clinics have been created to provide services for these children, and as a result there has been a significant improvement in life expectancy. Some cases of cystic fibrosis do occur in Pakistani children, but they are uncommon and usually caused by different mutations than those reported in European children. In districts with significant ethnic diversity, other genetic respiratory diseases may be clinically important. Thus, in Bradford there were 19 patients of South Asian origin with primary ciliary dyskinesia, another life-limiting condition with a major effect on the respiratory system [27]. Of these patients, 18 were of Pakistani origin and 1 was Bangladeshi, with the disease prevalence in Bradford Asian children calculated as 1 in 2,265 in contrast to previous estimates of 1 in 15,000 to 1 in 30,000 in the general UK population.

The increased awareness of primary ciliary dyskinesia has, in turn, led to increased rates of diagnosis. As a result, in Bradford there are now more children of Asian origin with primary ciliary dyskinesia $(\mathrm{n}=35)$ than children of all ethnicities with cystic fibrosis $(n=25)$, which clearly illustrates the need for clinical services to adapt in order to meet the needs of the ethnically diverse population in the city.

\section{Bleeding Disorders}

There have been few published studies of ethnic variations in bleeding disorders, but a 1997 paper from Bradford reported an increase in factor VII deficiency and platelet disorders among Pakistani patients [28]. Factor VII deficiency is an extremely rare autosomal recessive condition, but of the 16 patients attending the Bradford clinic, 11 were Pakistani and 5 were White British. Platelet disorders were also more common among the Pakistani $(\mathrm{n}=12)$ compared with the larger White British population $(\mathrm{n}=5)$, with Bernard-Soulier syndrome and Glanzmann's thrombasthenia being notable examples of this disease category.

\section{Chronic Ataxias in Children}

Ataxia may occur as a result of brain injury or infection, but most cases of chronic ataxia in children are due to rare genetic conditions. Unpublished data from Bradford Neurodisability Clinics listed 35 children with chronic ataxia, of whom 31 (88.6\%) were of Pakistani origin. The most common conditions diagnosed were Joubert syndrome ( $\mathrm{n}=8$, of whom 7 were Pakistani), inborn errors of metabolism ( $n=6$, of whom 5 were Pakistani), and EAST syndrome $(\mathrm{n}=3$, all Pakistani).

\section{Neuromuscular Conditions}

There is little published information on the prevalence and variety of neuromuscular diseases in UK Pakistani children, but there is strong evidence that suggests a significant increase in disorders of autosomal recessive origin. Patients attending the Martin House Children's Hospice in Yorkshire were reviewed for neuromuscular conditions, and South Asian patients were ascertained using South Asian name recognition software packages [29]. The hospice accepts children and young people from much of Yorkshire and the Humber region, where 87,900 (9.1\%) of 971,200 children are of Asian origin. In the Martin House Children's Hospice, $13.7 \%$ of all referrals with neuromuscular conditions were South Asian, rising to over $50 \%$ of those with 'other' neuromuscular diseases, that is, excluding Duchenne muscular dystrophy and spinal muscular atrophy [30]. A complementary analysis of clinical registers in Bradford has confirmed an excess of children of Pakistani origin with these disorders (table 5). 
Table 5. Profiles of Bradford children with neuromuscular conditions by ethnicity, September 2013

\begin{tabular}{llll}
\hline & Pakistani & White British & Others \\
\hline Duchenne muscular dystrophy & 4 & 3 & 3 \\
Congenital muscular dystrophy or myopathy & 17 & 3 & 1 \\
Hereditary sensorimotor neuropathy & 4 & 1 & 0 \\
Spinal muscular atrophy & 3 & 1 & 1 \\
Various neuromuscular disorders & 13 & 3 & 1 \\
\hline Total neuromuscular disorders & $41(70.7 \%)$ & $11(19.0 \%)$ & $6(10.3 \%)$ \\
\hline
\end{tabular}

\section{Visual Impairment}

In 2002, Schwarz et al. [31] reported that Bradford children of Pakistani origin were significantly more likely to have genetically linked visual disease and a positive family history than children of White British origin. According to the UK National Registration System for children with visual impairment, Bradford children represented approximately $1 \%$ of the total for the age group of 5-17 years in England, but they accounted for 3.5\% of the reported cases, and $3.0 \%$ of those with severe visual impairment. A 2011 letter published in Eye reported 2.26 cases of visual impairment per 1,000 in Bradford compared with 0.57 per 1,000 in the general population in England [32]. Although there was no accompanying ethnic breakdown for these data, it was thought that the increase was partly related to people of Asian origin [32].

\section{Deafness}

There is evidence that rates of deafness are increased in UK children of Pakistani origin [33, 34]; in Oldham, a 2005 paper reported permanent childhood hearing impairment in 4.64 per 1,000 Asian live births, compared to 1.34 per 1,000 in non-Asian live births [33]. In 2005, Yoong et al. [34] reported on 214 children with sensorineural hearing loss seen at Bradford clinics, 140 (65.4\%) of whom were Pakistani and 74 (34.6\%) were non-Pakistani. An earlier study [35], also carried out in Bradford, had reported an increased prevalence of hearing loss among Asian, mainly Pakistani, children of 4.69 per 1,000 compared with 1.38 per 1,000 among non-Asian children, and 44 of the Asian children had autosomal recessive deafness compared with 5 of the non-Asian children [35].

\section{Congenital Anomalies and Consanguinity}

A large majority of reports show increased rates of disabilities or medical conditions in the UK Pakistani community, and it is likely that most of the increase is accounted for by autosomal recessive conditions. It is acknowledged that this community has high rates of consanguineous marriage, but few of the studies directly link the specific conditions to parental consanguinity. An association between consanguinity and congenital anomalies has, however, been reported in numerous studies [4]. For example, in Norway the prevalence of congenital anomalies was $1.9 \%$ higher in babies born to first-cousin parents [36]; in a Turkish community the prevalence was also $1.9 \%$ higher [37], and in an Israeli Arab community the rates of congenital anomalies were $3.6 \%$ higher in the progeny of first cousins [38]. Consanguineous unions are, however, underpinned by a range of cultural, social and economic factors [39], which often have not been considered or controlled for in such investigations [40].

As part of the $\mathrm{BiB}$ birth cohort, a recent prospective study on 11,396 babies, 1,890 (17.7\%) of whom were of first-cousin parentage, examined possible associations between birth defects and a range of clinical, social and demographic factors [6]. In a multivariate model which adjusted for maternal deprivation, education, age, cigarette and alcohol consumption, the offspring of consanguineous unions had a relative risk of congenital anomaly of 2.10 (95\% CI 1.67-2.85) compared with their nonconsanguineous counterparts. The study confirmed the recognised protective effect of education in all ethnic groups analysed. More metabolic defects were diagnosed in the offspring of consanguineous parents, and since a majority of these disorders are autosomal recessive this was not a surprising observation. However, excess numbers of congenital microcephaly and hydrocephaly were also observed, as was an increase in the incidence of atrial septal defects in the babies of first-cousin parents which confirmed previous reports [41].

\section{Private Syndromes}

In addition to the almost 200 different autosomal recessive conditions seen in Bradford Pakistani children, we have many patients for whom there is not yet a diag- 
nosis, but who have a family history very suggestive of autosomal recessive inheritance. With further genetic studies a cause may be identified, as happened quite recently with 3 siblings who had an unusual pattern of epilepsy, ataxia, sensorineural deafness and renal tubular disease [42]. Collaboration with colleagues in London led to the identification of an affected relative elsewhere in England as well as an unrelated child from the Middle East, and genomic studies led to the first description of EAST syndrome, caused by mutations in the KCNJ10 gene [42]. Since the publication of this report, several additional UK patients have been diagnosed with the disorder, often of Pakistani heritage.

\section{Increased Numbers of Conditions Not Confirmed as}

Autosomal Recessive Mutations

In some ways the increase in conditions which are not obviously genetic raises the most interesting questions. Autosomal recessive conditions have long been recognised as increased in consanguineous populations. While most of the conditions so far mentioned are recognised as single-gene autosomal recessive disorders, several other disorders which may or may not have a genetic component are also seen at increased prevalence in UK Pakistani children. For example, except for some rare ataxic syndromes, cerebral palsy is not thought of as having a genetic basis, but a 1997 report from Bradford described both a significantly increased prevalence in Asian children and a positive family history in more than one quarter of these children [43]. Similar findings have been made in Saudi Arabia [44] and Turkey [45], and Mitchell and Bundey [46] reported on 18 Pakistani patients from 7 families in the English West Midlands, where there seemed to be a familial pattern of cerebral palsy, with a region of homozygosity identified at chromosome 2q24q25 in 3 of these families [47].

\section{Ethnicity, Consanguinity, Endogamy and Other Factors Causing Increased Prevalence}

The prior discussion has centred on reports of increased mortality and morbidity in Asian children, sometimes specifically identified as Pakistani; however, in a majority of cases a causal association with consanguinity remains unproven.

\section{Ethnicity}

A self-reporting system for ethnicity is used in Bradford hospital records, where patients are provided with a list of examples and requested to state their ethnicity and religion. In principle, this should enable a differentiation between Pakistani, Indian and Bangladeshi patients and families. In practice, however, the requisite information is missing from the records of $5-10 \%$ of patients. In research covering other districts or health regions with less specific ethnic labelling, South Asian name recognition software such as Nam Pehchan [29] or Onomap is often used. Unfortunately, these programs may not always distinguish between countries of origin and it would be helpful if we could produce accurate and detailed information from routine health records. Otherwise, reliance has to be placed on information obtained directly from the families by the research team, an approach which involves additional work and contact with the families and for which ethics approval is required.

\section{Consanguinity}

Information about genetic relationships between parents is not routinely requested or obtained at many clinics, and its collection may depend on the specific insight of the health professional. It can be introduced as a routine query but is sometimes seen as intrusive by Pakistani families who feel that the questioning is judgmental. And a 'yes' or 'no' option to the question may or may not elicit the correct response. So there are layers of complexity in what might seem to be relatively simple information gathering. When the patient is present in a consultation or research interview, it is usually possible to accurately establish ethnicity or the family relationship(s) of a couple. But relying on information previously gathered by another person can be fraught with problems, and occasionally of varying reliability.

\section{Endogamy}

While there is undoubtedly a major health problem that can be ascribed to high rates of cousin marriage, the picture is made much more complex by consanguinity in previous generations, and by the strict patterns of subcommunity endogamy prevalent in the Pakistani society. Many couples who are not cousins will be members of the same endogamous group, whose membership is based on traditional male lineages and usually identified by the term biraderi (or quom) [48]. To date, we have had limited success in exploring biraderi membership, and for frontline staff from another ethnic background to successfully comprehend and make enquiries about biraderi membership is difficult.

It has, however, been our experience that, for many extremely rare conditions, familial clusters are apparent 
with siblings, cousins and other relatives being affected. Sometimes, we are also made aware of relatives in other parts of the UK, or in Pakistan, who seem to have the same condition. While 200 different conditions are recorded in Bradford, many of them affect only very small numbers of patients, frequently in single figures, which raises the probability of founder mutations and genetic drift [9].

\section{Other Factors Influencing the Numbers of People with Genetic Conditions}

It is important to recognise that, apart from marriage customs, there may be other factors increasing the total number of Pakistani children with genetic conditions, including family size, and differing attitudes to antenatal screening and pregnancy termination. Some Pakistani mothers may only arrive in the UK in the later stages of pregnancy, when antenatal screening is no longer feasible, and opportunities for adequate counselling may be hindered by language barriers or limited genetic knowledge within the community.

Since the first transcultural genetic counselling service was set up in Yorkshire in 1987, advice has been available to clients in several South Asian languages, and similar initiatives have developed in other cities with large Pakistani communities. In Leicester, the GENIE project has aimed to increase the community understanding of genetics, with patient advocates recruited from the Asian population. More widely, Genetic Alliance UK has worked with the London Ideas GKP Translation Project to produce leaflets on genetic topics in a wide range of European and Asian languages (www.geneticalliance. org.uk/multilingual/index.html).

\section{Implications for Pakistan}

Data from Bradford on births of Pakistani origin between 2007 and 2010 revealed that $55 \%$ of the mothers and $59 \%$ of the fathers were born in Pakistan. Indeed a significant minority of firstborn children may have been conceived in Pakistan after the parents' marriage in that country. It therefore seems very likely that on investigation a similar profile of genetic disorders will be found in the Azad Kashmir region of Pakistan, from which a majority of these couples migrated. For example, $91 \mathrm{UK}$ Pakistani children were identified as having lysosomal storage disorders, and in the absence of equivalent popu- lation data from Pakistan these findings may be the closest we have to a relevant case series [Verity C., pers. commun.]

\section{Summary}

There is widespread evidence that UK children of Pakistani heritage have increased rates of many autosomal recessive conditions. Future studies should attempt to accurately define the ethnic background and degree of consanguinity, in the latter case possibly via genomic analysis. Improved recording of ethnicity as part of routine data gathering would be very useful. National studies involving genetic conditions should always consider ethnicity, which might give added insight into the findings and significantly assist in their translation into clinical practice. Specific research projects might also consider an enquiry into geographical, religious and biraderi background, as it seems likely that many genetic conditions are concentrated within these smaller sub-groups. Attempts should be made to estimate carrier prevalence for some autosomal recessive conditions, which could lead to a greater understanding of the role and influence of endogamy. It might also give clinically useful information for a more targeted diagnosis and possible future screening programmes.

The presence of disease clusters among the UK Pakistani population has already led to advances in genetic knowledge, and such research should be supported, particularly if conducted in collaboration with colleagues in Pakistan. Likewise, prevalence data for genetic conditions in the UK Pakistani population may usefully inform health provision in Pakistan, at least at a regional level.

\section{Acknowledgements}

I am deeply indebted to many people, who helped me both during the preparation of this paper and during my time in Bradford. Many colleagues including Stella Yeung, Kate Wildig, Nick Wood, Annette Jackson, Hannah Webb, Nicky Symons, Adrian Minford, Eduardo Moya and Anil Shenoy have willingly provided information and advice. Special mention should be made of Roger Parslow, Chris Verity, Anne-Marie Winstone, Lesley Stellitano, John Wright, Emily Petherick, Pam Craven, Gulshan Karbani, Amanda Bestwick, Dalvinder Hellawell and Paul Dawson. In particular, Prof. Bob Mueller and Prof. Alan Bittles have provided much encouragement and insight. Dr. Eamonn Sheridan provided much advice, encouragement and technical assistance during the evolution of this paper. 


\section{References}

1 http://www.ons.gov.uk/ons/taxonomy/index.html?nscl=Population+Estimates+by+ Ethnic+Group\#tab-data-tables.

2 The Bradford and District Infant Mortality Commission Report. 2006. http://www. bdimc.bradford.nhs.uk.

3 Bittles AH: Consanguinity and its relevance to clinical genetics. Clin Genet 2001;60:8998.

4 Bundey S, Alam H, Kaur A, Mir S, Lancashire RJ: Race, consanguinity and social features in birmingham babies: a basis for prospective study. J Epidemiol Community Health 1990;44:130-135.

5 Darr A, Modell B: The frequency of consanguineous marriage among British Pakistanis. J Med Genet 1988;25:186-190.

-6 Sheridan E, Wright J, Small N, Corry PC, Oddie S, Whibley C, Petherick ES, Malik T, Pawson N, McKinney PA, Parslow RC: Risk factors for congenital anomaly in a multiethnic birth cohort: an analysis of the Born in Bradford study. Lancet 2013;382:1350-1359.

7 Gresham D, Morar B, Underhill PA, Passarino $\mathrm{G}$, Lin AA, Wise C, Angelicheva D, Calafell F, Oefner PJ, Shen P, Tournev I, de Pablo R, Kucinskas V, Perez-Lezaun A, Marushiakova E, Popov V, Kalaydjieva L: Origins and divergence of the Roma (gypsies). Am J Hum Genet 2001;69:1314-1331.

8 Bittles AH: Consanguinity in Context. Cambridge, Cambridge University Press, 2012.

$\checkmark 9$ Bittles AH: Consanguinity, genetic drift, and genetic diseases in populations with reduced numbers of founders; in Speicher MR, Motulsky AG, Antonarakis SE (eds): Vogel and Motulsky's Human Genetics. Berlin, Springer, 2010, pp 507-528.

10 Norio R: Finnish disease heritage I: characteristics, causes, background. Hum Genet 2003;112:441-456.

- 11 Boyd PA, Armstrong B, Dolk H, Botting B, Pattenden S, Abramsky L, Rankin J, Vrijheid $\mathrm{M}$, Wellesley D: Congenital anomaly surveillance in England - ascertainment deficiencies in the national system. BMJ 2005;330:27.

12 https://www.gov.uk/government/news/ public-health-england-phe-welcomes-binocar-annual-report-on-congenital-anomalies.

13 Bundey S, Alam H: A five-year prospective study of the health of children in different ethnic groups, with particular reference to the effect of inbreeding. Eur J Hum Genet 1993;1:206-219.

14 Raynor P; Born in Bradford Collaborative Group: Born in Bradford, a cohort study of babies born in Bradford, and their parents: protocol for the recruitment phase. BMC Public Health 2008;8:327.
15 Wright J, Small N, Raynor P, Tuffnell D, Bhopal R, Cameron N, Fairley L, Lawlor DA, Parslow R, Petherick ES, Pickett KE, Waiblinger D, West J; Born in Bradford Scientific Collaborators Group: Cohort profile: the Born in Bradford multi-ethnic family cohort study. Int J Epidemiol 2013;42:978-991.

16 Hollowell J, Oakley L, Kurinczuk JJ, Brocklehurst P, Gray R: The effectiveness of antenatal care programmes to reduce infant mortality and preterm birth in socially disadvantaged and vulnerable women in high-income countries: a systematic review. BMC Pregnancy Childbirth 2011;11:13.

17 Fraser LK, Miller M, Hain R, Norman P, Aldridge J, McKinney PA, Parslow RC: Rising national prevalence of life-limiting conditions in children in England. Pediatrics 2012; 129:e923-e929.

18 Benson JWT: Recessive disorders and consanguineous marriage. BMJ 2005;331:1475.

19 Benson JWT, Korwariwalla S: Blackburn Asians with a family history of recessive disorders need intensive counselling regarding the risks associated with cousin marriage. Arch Dis Child 2004;89:G192.

20 Morton R, Sharma V, Nicholson J, Broderick $M$, Poyser J: Disability in children from different ethnic populations. Child Care Health Dev 2002;28:87-93.

21 Hutchesson AC, Bundey S, Preece MA, Hall SK, Green A: A comparison of disease and gene frequencies of inborn errors of metabolism among different ethnic groups in the West Midlands, UK. J Med Genet 1998;35: 366-370.

22 Verity C, Winstone AM, Stellitano L, Will R, Nicoll A: The epidemiology of progressive intellectual and neurological deterioration in childhood. Arch Dis Child 2010;95:361-364.

23 Smith NJ, Winstone AM, Stellitano L, Cox TM, Verity CM: Gm2 gangliosidosis in a UK study of children with progressive neurodegeneration: 73 cases reviewed. Dev Med Child Neurol 2012;54:176-182.

24 Corry PC: Intellectual disability and cerebral palsy in a UK community. Community Genet 2002;5:201-204.

25 Jackson AP, McHale DP, Campbell DA, Jafri H, Rashid Y, Mannan J, Karbani G, Corry P, Levene MI, Mueller RF, Markham AF, Lench NJ, Woods CG: Primary autosomal recessive microcephaly (MCPH1) maps to chromosome 8p22-pter. Am J Hum Genet 1998;63: 541-546.

26 Roberts E, Hampshire DJ, Pattison L, Springell K, Jafri H, Corry P, Mannon J, Rashid Y, Crow Y, Bond J, Woods CG: Autosomal recessive primary microcephaly: an analysis of locus heterogeneity and phenotypic variation. J Med Genet 2002;39:718-721.

27 O'Callaghan C, Chetcuti P, Moya E: High prevalence of primary ciliary dyskinesia in a British Asian population. Arch Dis Child 2010;95:51-52.
8 Macheta MP, Minford AMB, Parapia LA: Incidence of hereditary bleeding disorders in Bradford, UK: variation with ethnic group. Haemophilia 1997;3:292-294.

29 Cummins C, Winter H, Cheng KK, Maric R, Silcocks P, Varghese C: An assessment of the Nam Pehchan computer program for the identification of names of south Asian ethnic origin. J Public Health Med 1999;21:401406.

30 Fraser LK, Childs AM, Miller M, Aldridge J, Manning S, McKinney PA, Parslow RC: A cohort study of children and young people with progressive neuromuscular disorders: clinical and demographic profiles and changing patterns of referral for palliative care. Palliat Med 2012;26:924-929.

-31 Schwarz K, Yeung S, Symons N, Bradbury J: Survey of school children with visual impairment in Bradford. Eye (Lond) 2002;16:530534.

32 Kliner M, Fell G, Pilling RF, Bradbury JA: Visual impairment in children. Eye (Lond) 2011;25:1097.

-33 Mytton J, Mackenzie I: Observed and expected prevalence of permanent childhood hearing impairment in Oldham. J Public Health (Oxf) 2005;27:298-302.

-34 Yoong SY, Feltbower R, Spencer N, McKinney PA: Families affected by deafness: Hospital services uptake in a multiethnic population. Arch Dis Child 2005;90:454-459.

35 Parry G: Aetiology and prevalence of childhood hearing impairment in Bradford. Audiens 1995;20:25-29.

- 36 Stoltenberg C, Magnus P, Lie RT, Daltveit AK, Irgens LM: Birth defects and parental consanguinity in Norway. Am J Epidemiol 1997;145:439-448

37 Demirel S, Kaplanoglu N, Acar A, Bodur S, Paydak F: The frequency of consanguinity in Konya, Turkey, and its medical effects. Genet Couns 1997;8:295-301.

38 Zlotogora J, Shalev SA: The consequences of consanguinity on the rates of malformations and major medical conditions at birth and in early childhood in inbred populations. Am J Med Genet A 2010;152A:2023-2028.

39 Hamamy H, Antonarakis SE, Cavalli-Sforza LL, et al: Consanguineous marriages, pearls and perils: Geneva International Consanguinity Workshop Report. Genet Med 2011; 13:841-847.

40 Bittles AH, Black ML: Consanguinity, human evolution, and complex diseases. Proc Natl Acad Sci USA 2010;107(suppl 1):1779_ 1786.

41 Shieh JT, Bittles AH, Hudgins L: Consanguinity and the risk of congenital heart disease. Am J Med Genet A 2012;158A:12361241. 
42 Bockenhauer D, Feather S, Stanescu HC, et al: Epilepsy, ataxia, sensorineural deafness, tubulopathy, and kcnj10 mutations. N Engl J Med 2009;360:1960-1970.

43 Sinha G, Corry P, Subesinghe D, Wild J, Levene MI: Prevalence and type of cerebral palsy in a British ethnic community: the role of consanguinity. Dev Med Child Neurol 1997; 39:259-262.
44 al-Rajeh S, Bademosi O, Awada A, Ismail H, al-Shammasi S, Dawodu A: Cerebral palsy in Saudi Arabia: a case-control study of risk factors. Dev Med Child Neurol 1991;33:10481052.

45 Serdaroglu A, Cansu A, Ozkan S, Tezcan S: Prevalence of cerebral palsy in Turkish children between the ages of 2 and 16 years. Dey Med Child Neurol 2006;48:413-416.

46 Mitchell S, Bundey S: Symmetry of neurological signs in Pakistani patients with probable inherited spastic cerebral palsy. Clin Genet 1997;51:7-14.
47 McHale DP, Mitchell S, Bundey S, Moynihan L, Campbell DA, Woods CG, Lench NJ, Mueller RF, Markham AF: A gene for autosomal recessive symmetrical spastic cerebral palsy maps to chromosome 2q24-25. Am J Hum Genet 1999;64:526-532.

48 Shami SA, Grant JC, Bittles AH: Consanguineous marriage within social/occupational class boundaries in Pakistan. J Biosoc Sci 1994;26:91-96. 